\title{
Atmospheric Blocking Signatures in Total Ozone and Ozone Miniholes
}

\author{
DAVID BARRIOPEDRO \\ CGUL-IDL, Faculdade de Ciências, Universidade de Lisboa, Lisbon, Portugal \\ MANUEL ANTÓN \\ Departamento de Física, Universidad de Extremadura, Badajoz, Spain, and Centro de Geofísica de Evora, \\ Universidade de Évora, Évora, Portugal \\ José Agustín García \\ Departamento de Física, Universidad de Extremadura, Badajoz, Spain
}

(Manuscript received 6 November 2009, in final form 25 February 2010)

\begin{abstract}
This paper analyzes the statistical relationship between the total ozone column (TOC) and atmospheric blocking using 40-yr European Centre for Medium-Range Weather Forecasts (ECMWF) Re-Analysis (ERA-40) data for the 1978-98 period, with special emphasis on winter and the European and eastern Pacific sectors. Regional blocking occurrence is accompanied by a decrease of TOC within the anticyclonic circulation region and a distinctive ozone increase upstream and downstream (upstream and south) in the Pacific (European) sector. Blocking significantly enhances the likelihood of low TOC extremes, especially over the Scandinavian and the Alaska Peninsulas, where more than $50 \%$ of winter blocks lead to TOC values in the lowest tail of the distribution. The relationship between ozone miniholes and blocking is confined to the high latitudes of both basins and is strong in Europe, where about half of the ozone miniholes occur simultaneously with blocking. Blocking-related ozone miniholes (blocking ozone miniholes) are also among the most intense and persistent. Although blocking activity does not drive the interannual variability of regional ozone miniholes, blocking ozone miniholes account for up to two-thirds of the total observed trend of ozone miniholes in Europe. The polar vortex is proposed as a feasible candidate for explaining the enhanced coupling of blocking and ozone miniholes in Europe and its long-term modulation. Blocking ozone miniholes are consistent with an almost purely dynamic origin caused by horizontal transport of ozone-poor air and vertical motions working together at different levels to reduce ozone content. Although the contribution of the former is dominant, accounting for two-thirds of ozone reduction in the 330-850-K column, the effect of the latter becomes a distinctive feature of blocking ozone miniholes.
\end{abstract}

\section{Introduction}

Variations in the total ozone column (TOC) have received an increased amount of attention since the discovery of the springtime ozone hole over Antarctica (Farman et al. 1985). Ozone depletion was attributed to the activation of stratospheric chlorine and bromine radicals in the presence of sunlight via heterogeneous reactions on the surface of polar stratospheric clouds (PSCs), which form at low temperatures in the isolated polar vortex

Corresponding author address: D. Barriopedro, CGUL-IDL, Faculdade de Ciências, Ed. C-8, Universidade de Lisboa, Campo Grande, 1749-016 Lisbon, Portugal.

E-mail: dbarriopedro@fc.ul.pt (e.g., Solomon 1999). In the 1990s, chemical TOC depletion was also observed in the Arctic ( 20\%-30\%), although winter-spring Arctic TOC is highly variable and 160 Dobson units (DUs; 30\%) higher than in the Antarctica (Staehelin et al. 2001). An ozone decline at midlatitudes was also noticed (Stolarski et al. 1991), the largest decreases occurring over $35^{\circ}-60^{\circ} \mathrm{N}$ during the winter-spring season (e.g., Staehelin et al. 2001). Subsequent studies confirmed large interannual and interdecadal variability superimposed on a statistically significant, but not linear, year-round decline in the northern midlatitude TOC from the late 1970s to the mid1990s and a subsequent recovery (Harris et al. 2008).

The origin of ozone losses at midlatitudes is not as clear as in the polar regions, since both photochemical (e.g., 
Solomon et al. 1996) and dynamical (e.g., Appenzeller et al. 2000) mechanisms can work together to reduce the TOC values. However, model experiments (Fusco and Salby 1999), observational studies (Peters et al. 1995; Hood et al. 1997; Peters and Entzian 1999), and statistical analyses (Petzoldt et al. 1994; McCormack and Hood 1997; Steinbrecht et al. 1998; Hood and Soukharev 2005) point to an important dynamical contribution to the midlatitude winter-spring ozone decrease, induced by changes in the atmospheric circulation that may explain approximately one-third of the observed lower-stratosphere trend (e.g., Randel et al. 2002; Hudson et al. 2006).

It has long been recognized that upper-troposphere dynamics contribute to ozone variability, on time scales ranging from those of synoptic weather systems (Orsolini et al. 1998) to interannual (Orsolini and Limpasuvan 2001; Orsolini and Doblas-Reyes 2003). TOC values often experience strong reductions that can exceed $50 \%$ of average values during the passage of weather systems (Dobson et al.1929). These transient and localized events of reduced ozone were called ozone miniholes (Newman et al. 1988). They are frequently observed from late autumn to early spring at extratropical latitudes of both hemispheres (e.g., Peters et al. 1995; James 1998; Hood et al. 2001), in close spatial correlation to the storm-track region and the jet stream (Orsolini et al. 1998). Though their scale and duration are considerably smaller than those of the polar ozone hole, ozone miniholes can enhance UV radiation over populated areas (e.g., Semane et al. 2002; Orsolini et al. 2003; Antón et al. 2007, 2008) and hence, can cause adverse effects on human health and ecosystems, particularly at low to middle summer latitudes.

Recent studies suggest an increasing frequency of winter-spring ozone miniholes over the Euro-Atlantic sector since at least the 1980 s, particularly during the 1990s (e.g., James 1998; Hood et al. 1999; Bojkov and Balis 2001), which may account for up to one-third of the observed TOC trend in the $40^{\circ}-65^{\circ} \mathrm{N}$ latitudinal belt (Reid et al. 2000). Regional dynamical changes seem to have contributed partially to this increase (Brönnimann and Hood 2003), in agreement with the effects of the North Atlantic Oscillation (NAO) on the ozone minihole frequency (Orsolini and Limpasuvan 2001).

During an ozone minihole event, ozone is usually not destroyed and, hence, these events are caused mainly by dynamical rather than photochemical processes (e.g., Peters et al. 1995; Reid et al. 2000; Hood et al. 2001). As ozone varies in response to vertical motions and horizontal advection, they both play a crucial role in ozone minihole development (e.g., Iwao and Hirooka 2006). These dynamical processes are usually associated with upper-tropospheric anticyclones and ridging flows. A special subset of this type of system is atmospheric blocking, that is, quasi-stationary and persistent highlatitude anticyclonic systems with a strong meridional component that interrupts the normal zonal flow (e.g., Rex 1950; Barriopedro et al. 2006, 2010). Several case studies of ozone miniholes associated with blocking events have been described in the boreal winter-spring (Farman et al. 1994; Engelen 1996; Petzoldt et al. 1994) and austral autumn (Canziani et al. 2002) seasons. In summer, ozone miniholes have also been reported to occur in association with blocking and southern shifts of the ozone-poor Arctic pool, which develops due to ozone gas-phase chemistry destruction rather than PSC chemistry (Orsolini et al. 2003; Orsolini and Nikulin 2006). Further studies analyzed the relationship between blocking and ozone miniholes at interannual time scales over fixed locations (Koch et al. 2005) or employing large-scale climate patterns (Orsolini and DoblasReyes 2003). Nevertheless, no systematic or detailed analyses have been conducted to quantify the degree of association between both phenomena.

The main objective of this study is to fingerprint the spatial signatures of blocking in TOC variability and, more precisely, 1) to evaluate the blocking impacts in the daily mean and extreme TOC distributions, 2) to assess the statistical linkage between blocking and ozone miniholes, 3 ) to estimate the blocking contributions to ozone minihole variability, and 4) to identify statistical and dynamical differences in ozone miniholes associated with blocking. The paper is organized as follows: the data are described next, followed in section 3 by the methodology used to identify blocking and ozone miniholes. Section 4 is devoted to the main results, and our conclusions are outlined in the last section.

\section{Data}

Daily data for the Northern Hemisphere (NH) have been extracted from the 40-yr European Centre for Medium-Range Weather Forecasts (ECMWF) ReAnalysis (ERA-40) reanalysis at $2.5^{\circ} \times 2.5^{\circ}$ resolution (Uppala et al. 2005). Single-level data include: 1) potential temperature $\theta$ and zonal wind at the dynamical tropopause (defined as the surface of $2 \mathrm{PVU} ; 1$ PVU = $10^{-6} \mathrm{~m}^{2} \mathrm{~K} \mathrm{~s}^{-1} \mathrm{~kg}^{-1}$ ) and 2) TOC in Dobson units $\left(1 \mathrm{DU}=10^{3}\right.$ atmosphere-cm, i.e., the thickness in thousandths of a centimeter of the TOC at standard pressure and temperature). The ozone mass mixing ratio in kilograms per kilogram, pressure in Pascals, and potential vorticity (PV) fields are also obtained for 15 isentropic levels (from 265 to $850 \mathrm{~K}$ ).

Since the end of 1978 onward (except for 1989-90), ozone observations were assimilated in ERA-40 from 
the Total Ozone Mapping Spectrometers (TOMS) and the Solar Backscattered UltraViolet (SBUV) instruments on various satellites [mostly Nimbus-7 and $\mathrm{Na}$ tional Oceanic and Atmospheric Administration-9 and -11 (NOAA-9 and -11). However, as ozone is a model variable, ozone fields are also available for 1957-72 (presatellite) and 1973-78 (satellite without ozone data). By using independent ground-based Dobson observations, as well as satellite and ozonesonde data, Dethof and Hólm (2004) reported a realistic TOC field in the ERA-40 reanalysis, especially after 1978 (relative differences were less than $5 \%$, typically above observations). However, certain problems were reported for $\mathrm{NH}$ winter ERA-40 profiles; these profiles showed a tendency to place the ozone maximum at lower altitudes than were observed. These model errors were attributed to the lack of vertically well-resolved observations, thus calling for caution in those analyses based on ozone profile data.

The study is confined to 1978-98, which approximately coincides with the ERA-40 period that includes satellite ozone data. The analysis is performed for the whole year and for the $\mathrm{NH}$, but most of the results presented here will focus on the extended winter season (DecemberMarch, DJFM) and the Euro-Atlantic and Pacific-North America regions.

\section{Methods}

The characterization of blocking and ozone miniholes is performed from a twofold perspective, following the algorithms defined below. The former employs a gridpoint description based on the $2 \mathrm{D}$ clusters of grid points that characterize their daily patterns. The latter makes use of the characteristics of individual episodes, including persistence, mean intensity (i.e., amplitude of the anomaly), and extension of the $2 \mathrm{D}$ pattern.

\section{a. Blocking detection}

The diagnosis of blocking is based on absolute and anomaly fields of $\theta$ over a grid $(\lambda, \phi)$ of $(n i, n j)$ points and $(\delta \varphi, \delta \alpha)$ latitude-longitude resolution. The anomaly field is computed by removing a running annual mean and the seasonal cycle (Barriopedro et al. 2010). Daily blocks are identified as $2 \mathrm{D}$ contiguous grid points satisfying two conditions: 1) their anomalies are above a given threshold $\theta_{t}^{\prime}$ and 2) they are located north of a reference latitude $\phi_{c}$ for which a meridional $\theta$ gradient reversal exists. In other words, a block is detected if the meridional $\theta$ gradient around $\phi_{c}$ [i.e., the zonal index ZI in Eq. (1) below] is positive for at least one longitude within a cluster of grid points with anomalies exceeding $\theta_{t}^{\prime}$ :

$$
\begin{aligned}
& \mathrm{ZI}\left(\lambda, \phi_{0}\right)=\frac{2}{\Delta \phi} \cdot\left[\sum_{\phi=\phi_{0}(\lambda, k)}^{\phi=\phi_{0}(\lambda, k)+\Delta \phi} \theta(\lambda, \phi)-\sum_{\phi=\phi_{0}(\lambda, k)-\Delta \phi}^{\phi=\phi_{0}(\lambda, k)} \theta(\lambda, \phi)\right]>0 \quad 0 \leq \lambda \leq n i \cdot \delta \alpha \\
& \phi_{c}(\lambda)-\Theta(k) \leq \phi_{0}(\lambda, k) \leq \phi_{c}(\lambda)+\Theta(k) \\
& \Theta(k)=k \cdot \delta \varphi \quad 0 \leq k<\Delta \phi / 2 \cdot \delta \varphi .
\end{aligned}
$$

The 1-standard-deviation level of the total daily $\theta$ anomaly distribution for those grid points north of $\phi_{c}$ is adopted as $\theta_{t}^{\prime}(\sim 8 \mathrm{~K})$. The zonal index formulation follows that of Pelly and Hoskins (2003). The latitudinal range used to compute the meridional $\theta$ gradient $\Delta \phi$ is indicative of the latitudinal scale of the block, which is fixed at $15^{\circ}$. For a blocking occurrence, $\phi_{c}$ can be inferred from the region of maximum synoptic activity (Pelly and Hoskins 2003). Here, $\phi_{c}$ is identified for each longitude and day of the calendar year as the latitude with maximum climatological variance of 5-day high-pass zonal wind filter outputs in 90-day centered running windows. To account for variations relative to the seasonal mean, $\phi_{c}$ is also allowed to oscillate a given amount $\Theta$ (up to $5^{\circ}$ ) around its mean value.

Additional criteria such as the requirement of a minimum 2D extension $\left(\sim 10^{6} \mathrm{~km}^{2}\right)$, some fraction of overlapping between successive daily blocks $(\sim 50 \%)$, and temporal persistence (four uninterrupted days) are also demanded to account for the typical scales of the block and its spatiotemporal evolution. These thresholds are close to those adopted in the literature (e.g., Pelly and Hoskins 2003; Schwierz et al. 2004). For further details on the detection scheme, the reader is referred to Barriopedro et al. (2010).

\section{b. Minihole definition}

Different definitions for ozone miniholes can be found in the literature. Some authors apply absolute fixed TOC thresholds lower than 300 DU (McCormack and Hood 1997), 225 DU (Petzoldt 1999; Brönnimann and Hood 2003) or 220 DU (Bojkov and Balis 2001). Alternative definitions employ relative values such as the standard deviation (Koch et al. 2005; Antón et al. 2008) or timevariant thresholds lower than the monthly or the annual mean by some quantity between 70 and 80 DU (James 
1998; Krzyscin 2002; Iwao and Hirooka 2006). Additional considerations are mandatory regarding the location and characteristic scales of ozone miniholes. Latitudinal limits often range between $30^{\circ}-35^{\circ}$ and $65^{\circ}-70^{\circ}$ (James 1998 ; Iwao and Hirooka 2006) to avoid counting ozone miniholes within the subtropics and in the polar ozone hole, respectively. Subsynoptic features are filtered out by smoothing the data (James 1998), applying minimum extensions of approximately $5 \times 10^{5} \mathrm{~km}^{2}$ (Bojkov and Balis 2001; Iwao and Hirooka 2006) or minimum durations of 2-3 days (Bojkov and Balis 2001; Krzyscin 2002).

As in the case of atmospheric blocking, the TOC anomaly field is computed here by removing the mean seasonal cycle plus a running annual mean, thus accounting for the annual cycle and long-term variations of TOC (James 1998), respectively. Then, ozone miniholes are identified as areas of local TOC anomaly below -55 DU extending over areas greater than $2.5 \times 10^{5} \mathrm{~km}^{2}$ and containing minimum TOC anomalies lower than -70 DU. The threshold of -55 DU fits the 2-standard-deviation level of the anomaly TOC distribution, and allows for size determination and tracking of ozone miniholes. The second threshold $(-70 \mathrm{DU})$ is close to the first percentile of the TOC anomaly distribution and it was adopted to maintain criteria as close as possible to previous definitions. In addition, a minimum absolute TOC value below 310 DU was required within the $2 \mathrm{D}$ TOC anomaly to filter out deep anomalies over climatological regions of large TOC levels, which in fact are not miniholes.

The minimum latitude for minihole occurrence is computed for each day of the period as the latitude where the mean TOC of the 90-day centered window crosses 300 DU. No northern latitudinal limits are imposed on the detection scheme. Instead, events are not considered ozone miniholes if (a) the extension exceeds $1.25 \times$ $10^{7} \mathrm{~km}^{2}$, (b) the southernmost latitude is north of $65^{\circ} \mathrm{N}$, or (c) the northernmost latitude is $90^{\circ} \mathrm{N}$. These requirements were found to be sufficient to exclude polar ozone holes. Finally, the persistence of minihole events was computed by tracking the $2 \mathrm{D}$ anomalies on successive days, so that an ozone minihole is considered the next position of a previous one if their areas overlap by any amount. As in previous studies, a minimum duration criterion is not required (e.g., James 1998; Iwao and Hirooka 2006).

\section{c. Blocking and nonblocking ozone miniholes}

An example of the detection methods is shown in Fig. 1 for 18 January 1979. The ozone minihole over northern Europe (Fig. 1a) was also reported by Petzoldt (1999) (on 19 January) using satellite data derived from TOMS. The location and anomaly amplitude of this minihole are in a)

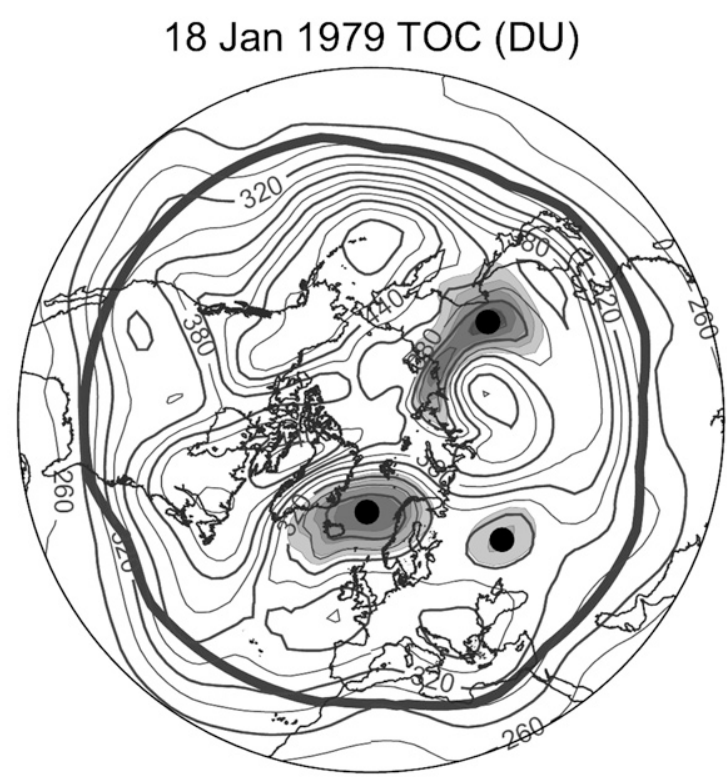

b)
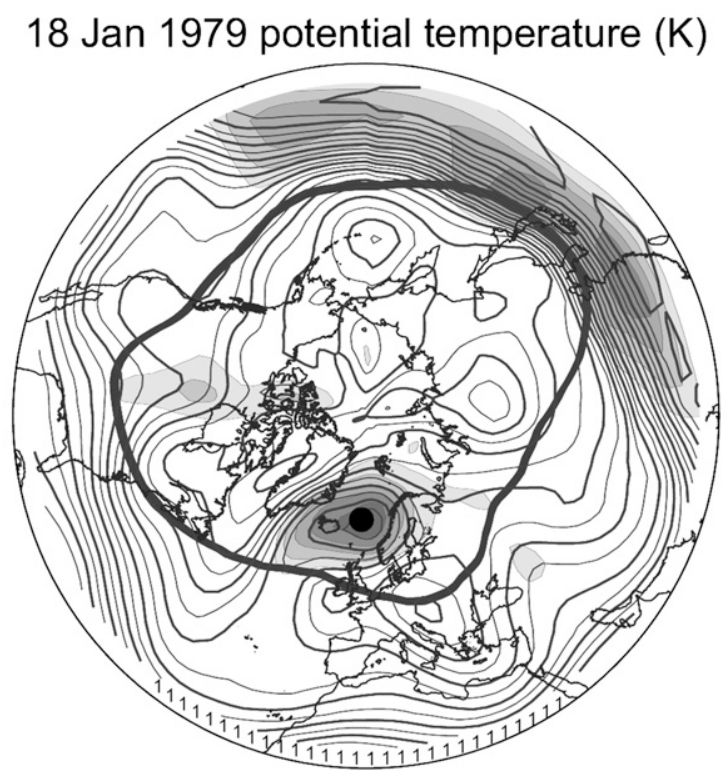

FIG. 1. Examples of (a) ozone miniholes and (b) blocking on 18 Jan 1979, as detected by the objective algorithms. Contour lines represent (a) TOC (DU) and (b) $\theta$ on the 2-PVU surface (K). Shaded areas are anomalies with a contour interval $(\mathrm{CI})$ of $-15 \mathrm{DU}(5 \mathrm{~K})$ starting at $-55 \mathrm{DU}(8 \mathrm{~K})$. Black points indicate the centers of ozone miniholes and blocking. Thick gray lines denote the minimum latitude for minihole occurrence $(\sim 300-\mathrm{DU}$ isoline $)$ and $\phi_{c}$ for blocking occurrence, respectively. Numbers along $22.5^{\circ}$ reflect local reversals in $\phi_{c}$ according to ZI [Eq. (1)]. See text for details.

good agreement with those reported therein, thus supporting the usefulness of ERA-40 for diagnosing ozone miniholes. Figure 1b illustrates the accompanying dynamical situation. Absolute and anomaly $\theta$ fields over 
northern Europe are almost collocated with those of TOC and reproduce similar signature patterns. The mean $\theta$ distribution, characterized by a poleward decrease, is reversed over western Europe, thus indicating the presence of a block with a warmer tropopause north of the mean jet stream position.

Figure 1a also reveals two ozone miniholes unrelated to blocking. Thus, in order to quantify the statistical linkage between blocking and ozone miniholes, the latter have been classified into two categories: accompanying or not accompanying blocking. The principle is based on overlapping arguments, depending on whether the ozone minihole is spatiotemporally coherent with the occurrence of a block. Thus, an ozone minihole is said to occur in association with a block (hereafter, blocking ozone minihole) if their areas overlap. Otherwise, it is classified as a nonblocking ozone minihole.

The subsequent analyses will focus on the Euro-Atlantic (EUR; $10^{\circ} \mathrm{W}-35^{\circ} \mathrm{E}$ ) and the Pacific-North American (PAC; $170^{\circ} \mathrm{W}-125^{\circ} \mathrm{W}$ ) sectors, whose limits encompass continental areas with maximum blocking activity. This approach is very useful for deriving specific regional features but it requires a criterion to attribute daily and episodic occurrences to a given sector. Here, the daily occurrence of an episode is assigned to that sector where the location of the center lies, whereas a given episode belongs to the sector where it spends the most time during its life cycle. The center of the minihole will be identified by the minimum TOC anomaly within the $2 \mathrm{D}$ enclosed area, whereas in the case of blocking it is assigned to the mass center of the $2 \mathrm{D}$ pattern.

\section{Results}

\section{a. Climatological features}

A preliminary inspection of blocking and ozone miniholes frequencies (not shown) revealed a marked seasonal blocking variability that peaks in late winter and early spring, in agreement with previous climatologies (e.g., Barriopedro et al. 2006). Ozone miniholes follow an analogous but more pronounced annual cycle characterized by a period of activity between October and May and maximum occurrence in mid- to late winter. Figure 2 represents the climatological spatial frequency distribution of blocking and ozone miniholes for their most active seasons. By virtue of their specific time scales and the different rationales employed in their definitions, several distinctive features can be noted about the blocking and ozone minihole climatologies regarding the degree of incidence and the location and extension of the action centers. For instance, blocks are more frequent and occur at slightly higher latitudes than ozone miniholes. a)

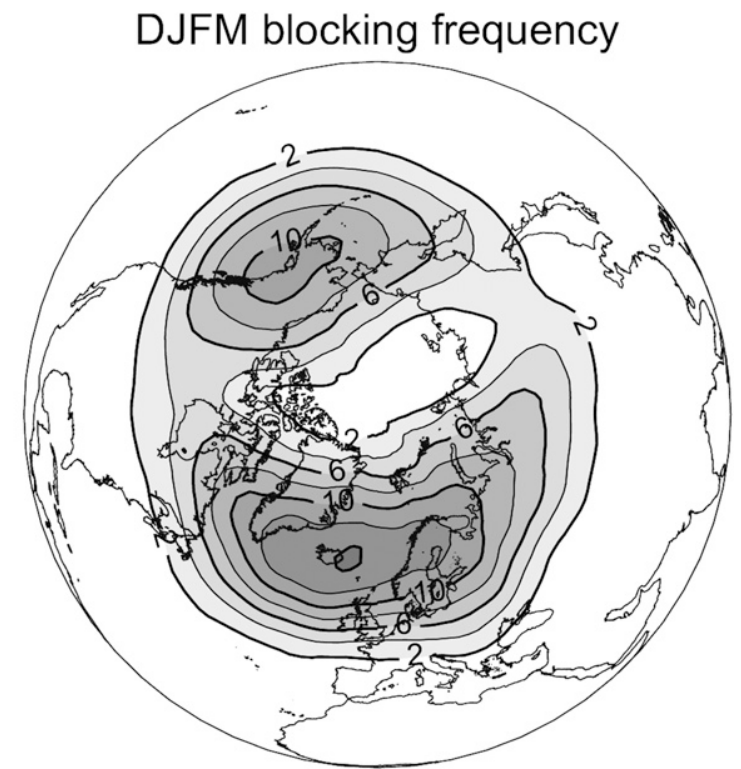

b)

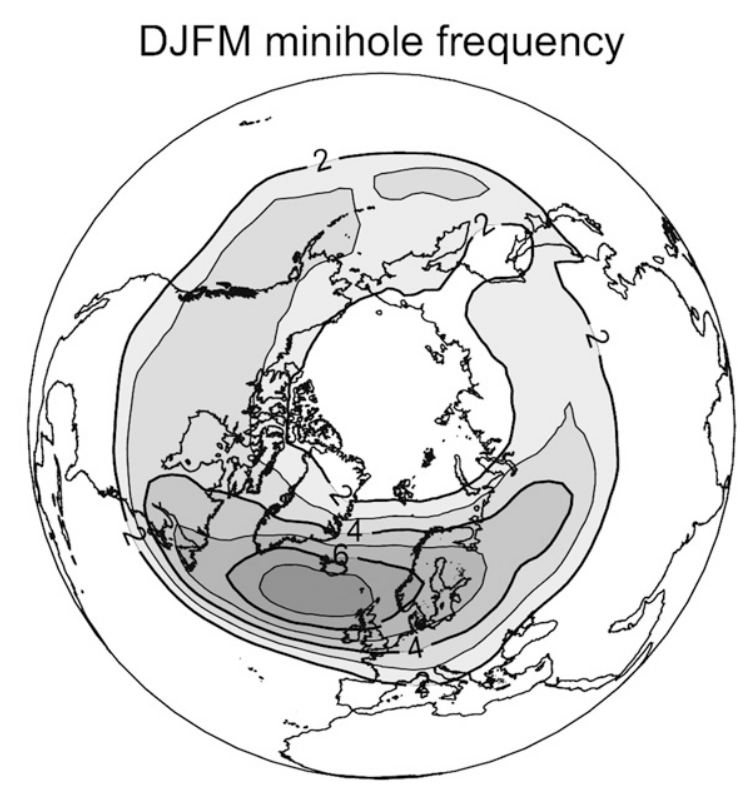

FIG. 2. Climatological DJFM mean frequencies of (a) blocking and (b) ozone miniholes. The frequency is expressed in percentage of the total number of DJFM days. Only frequencies above $2 \%$ are shown.

Two main sectors of blocking activity are observed over the eastern sides of the Atlantic and Pacific Oceans, coinciding with the climatological areas of wave amplification and the exit zones of the storm tracks (Fig. 2a). The Atlantic center is broader and more active than its Pacific counterpart by a factor of 2 . These results compare well with observational climatologies based on standard pressure levels (e.g., Barriopedro et al. 2010) and dynamical indicators (e.g., Croci-Maspoli et al. 2007). 
The ozone minihole distribution (Fig. 2b) also highlights typical signatures reported in previous studies (e.g., James 1998; Bojkov and Balis 2001; Krzyscin 2002). The maximum concentration of ozone miniholes is confined to extratropical latitudes, intimately linked to the transient eddy activity along the storm-track region. They are also more prominent over the Atlantic Ocean, where up to $7 \%$ of all winter days have an ozone minihole, whereas in the Pacific, maximum centers cannot be discerned from the background activity. This pronounced spatial asymmetry resembles (and may account for) that observed in the storm-track patterns of TOC [i.e., TOC fluctuations on synoptic time scales; Orsolini et al. 1998]. The higher recurrence of Atlantic ozone miniholes as compared to the almost null Pacific activity has been explained by different causes: 1) the stratospheric polar vortex, whose common shift toward Europe may help to amplify the dynamical ozone decrease therein (Petzoldt et al. 1994); 2) more frequent blocking activity in the Atlantic region (James 1998); and/or 3) the characteristic weak cyclonic meridional wind shear of the Atlantic region (Hood et al. 1999), which is a proxy for the occurrence of anticyclonic Rossby wave-breaking events associated with poleward intrusions of subtropical ozone-poor air (Peters and Waugh 1996).

In the next section the mean and extreme TOC distributions will be examined in order to identify TOC patterns associated with blocking, regardless of whether they correspond to an ozone minihole or not. In a following subsection, the statistical linkage between blocking and ozone miniholes will be assessed.

\section{b. TOC patterns under blocking occurrence}

To derive regional TOC signatures during blocking regimes, composites have been computed for those winter days when a block center was detected over any of the two main regions of occurrence (Fig. 3). Standard features of blocked flow patterns are mirrored in the TOC fields, which reveal poleward excursions of subtropical ozone-poor air into the middle and high latitudes, leading to low values of TOC over localized regions of high latitudes. Under EUR (PAC) blocking, maximum TOC reductions spread over the Scandinavian (Alaska) Peninsula, whereas the western Mediterranean and southern Greenland (central North America and eastern Asia) are affected by TOC increases. These TOC increases are symptomatic of equatorward intrusions of high-latitude low- $\theta$ air and cyclonic wave breaking, which is typically tied to the strong meridional circulation around the blocking high (e.g., Tyrlis and Hoskins 2008b).

Moreover, EUR (PAC) blocks tend to induce a dipolar (tripolar) anomaly structure superimposed on a tilted-reversal (omega shape) wave pattern in the TOC a)

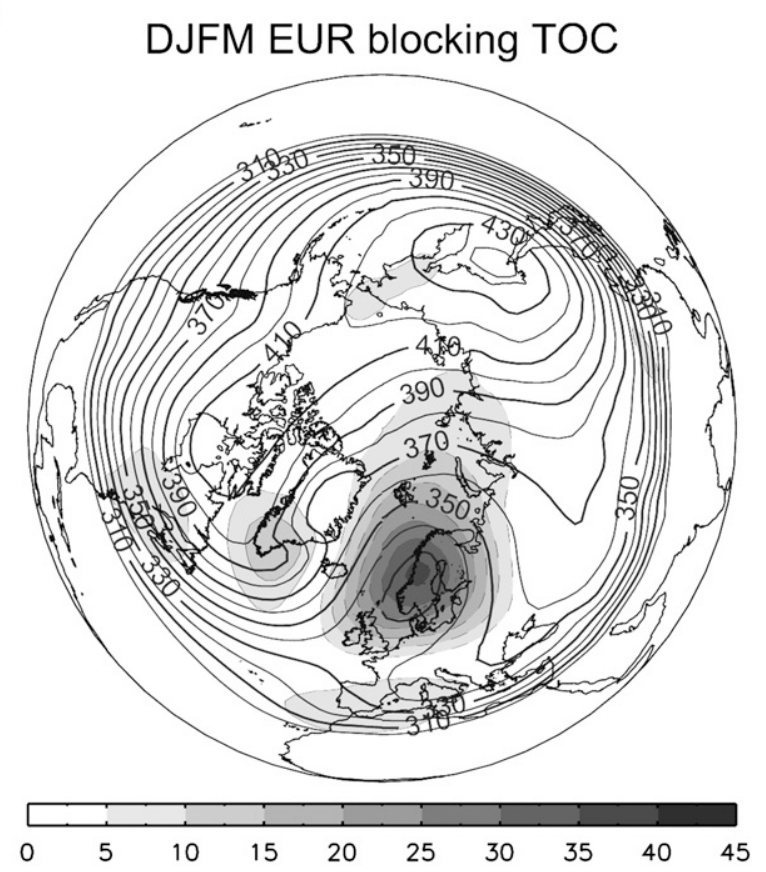

b)

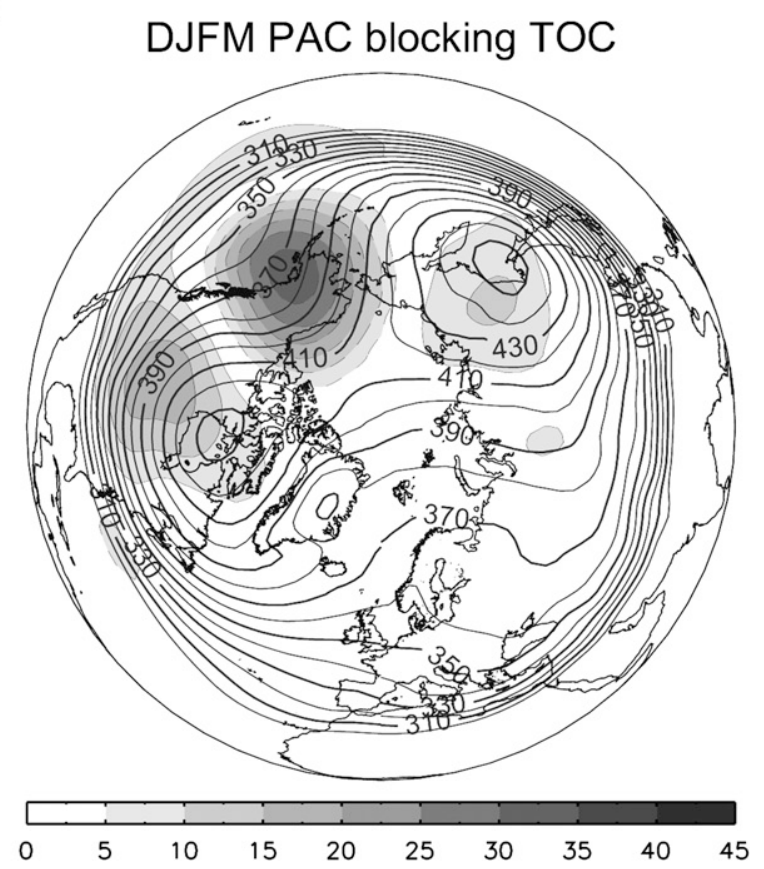

FIG. 3. Composites of the TOC (contours) and its absolute anomaly (shaded areas) for DJFM blocking days in (a) EUR and (b) PAC. Gray-shaded areas contoured by solid (dashed) lines indicate positive (negative) TOC anomalies.

field. Similar regional blocking signatures have been reported from PV (Altenhoff et al. 2008), $\theta$ (Tyrlis and Hoskins 2008b), and geopotential height (Barriopedro et al. 2010) fields, further supporting the idea that omegalike blocks are more frequent in PAC, whereas 
dipolar blocks tend to occur in EUR. Therefore, regional features in TOC signatures may be caused by the degree of incidence of each type of block (omega versus dipolar) over each basin. Tyrlis and Hoskins (2008b) explained this characteristic morphology of regional blocking from a wave-breaking perspective. They found that blocking typically corresponds to anticyclonic wavebreaking events resulting from the amplification of the climatological ridge. However, in the eastern Atlantic (Pacific), the region with maximum synoptic activity lies close to (north of) the jet stream and, hence, the breaking tends to occur equatorward (poleward) of the jet, favoring an anticyclonic (cyclonic) wind shear environment and a SW-NE (non-) tilted planetary wave structure.

In addition to the mean distributions, regional blocking impacts upon the extreme TOC distribution could be expected. To quantify the statistical relationship between blocking and local TOC minima, low TOC extremes have been identified at each grid point from the lower tercile of its daily winter anomaly distribution. Then, the percentage of regional blocking days coexisting with TOC extremes at each grid point is computed and compared to that expected by random chance (i.e., 33.3\%). The local significance of the departures from the expected value is estimated with a binomial test ( $95 \%$ confidence level) after correcting for autocorrelation (Wilks 1995). The likelihood of regional blocking days being concurrent with TOC minima is depicted in Fig. 4. Those regions in Fig. 3 characterized by blocking-induced decreases in the mean value of TOC also experience a shift toward more frequent extremes of low TOC. In particular, under EUR (PAC) blocking, TOC minima are more likely to occur over most of northern Europe (northwestern America), with more than $50 \%$ of the blocking days leading to extreme low TOC values in central Scandinavia (Alaska). Conversely, the occurrence of TOC minima over the western Mediterranean and central North America is not significantly related to blocking, in agreement with the localized increases of mean TOC content therein (Fig. 3). In terms of affected areas and significance, there are few changes if the lower quartile or the 10th percentile is adopted as a threshold for the extreme definition. Accordingly, blocking regimes are expected to enhance the rate of occurrence of ozone miniholes in high latitudes but not in lower latitudes.

\section{c. Ozone miniholes and blocking occurrence}

Overall, the degree of coincidence between ozone miniholes and blocking is noticeable for all months with maximum activity (Fig. 5a). On an annual average, the number of blocking ozone miniholes almost reaches $25 \%$ of all episodes. By sectors, EUR ozone miniholes a)
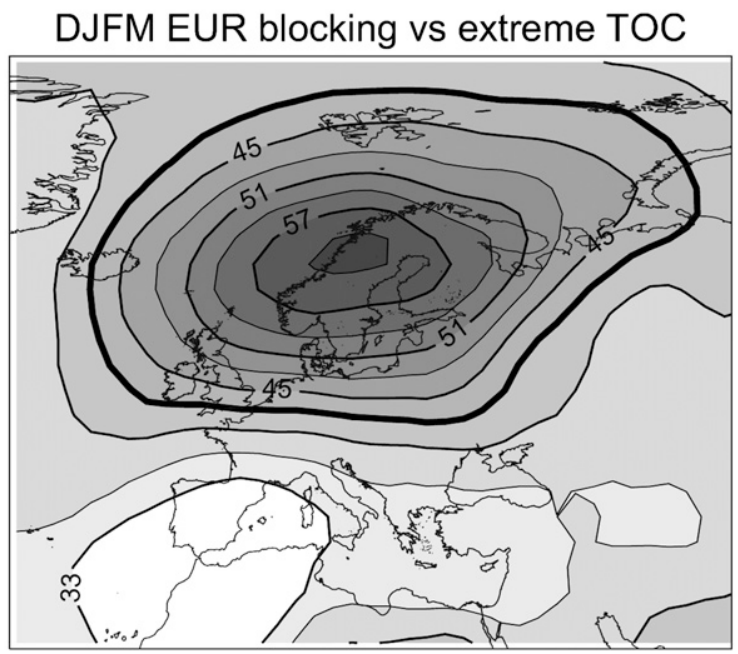

b)
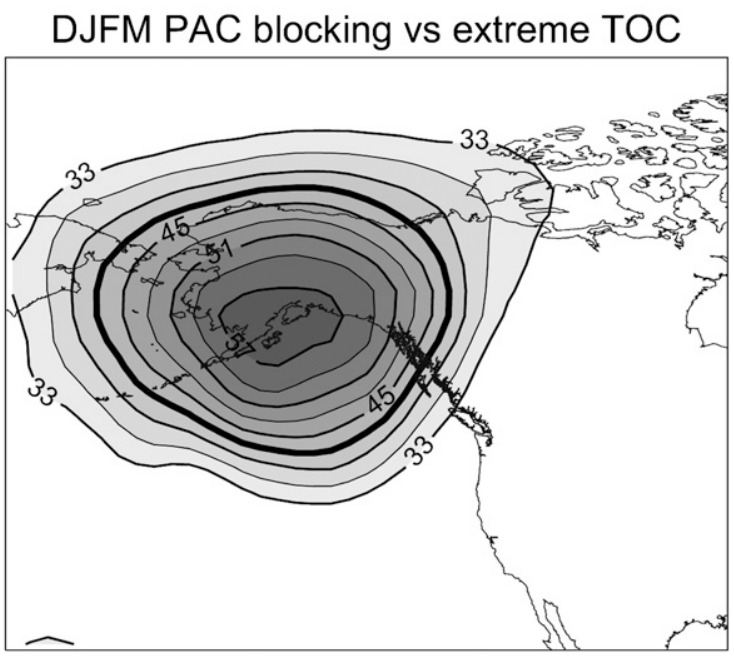

FIG. 4. Percentage of (a) EUR and (b) PAC blocking days in DJFM with local TOC anomalies below the lower tercile of its winter distribution. Solid lines and shaded areas denote those values exceeding the expected value $(33.3 \%)$ with CIs of $3 \%$. The thick solid line indicates the $95 \%$ confidence threshold based upon a binomial test.

are more related to blocking occurrence, with one-third of ozone minihole events being concurrent with blocking, as compared to the one-fifth of the PAC sector. As concerns the statistical characteristics of individual events, blocking ozone miniholes are on annual and hemispheric averages more persistent, intense, and have larger sizes than nonblocking ozone miniholes (Figs. $5 b$ and $5 c$ ). The differences are significant at $p<0.05$ after a two-tailed Student's $t$ test. Similar behavior is observed in each sector through the year, although the significance and magnitude of these linkages vary with season and region, being more prominent in EUR than in PAC (see Table 1 for the corresponding parameters during the DJFM season). 
a)

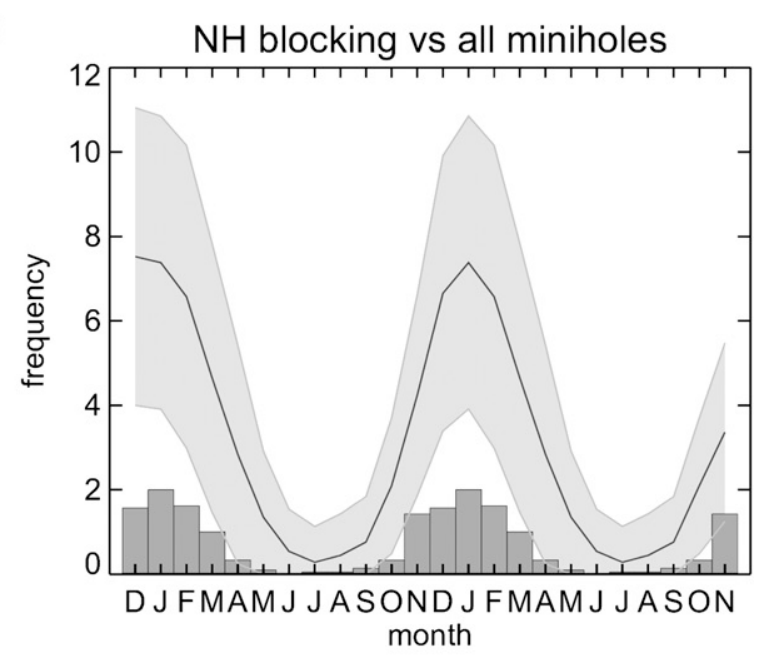

b)

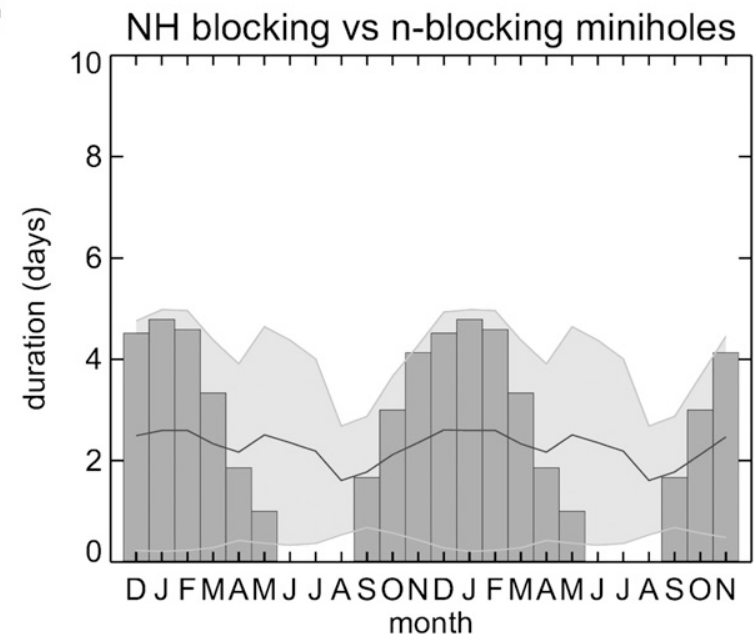

c)

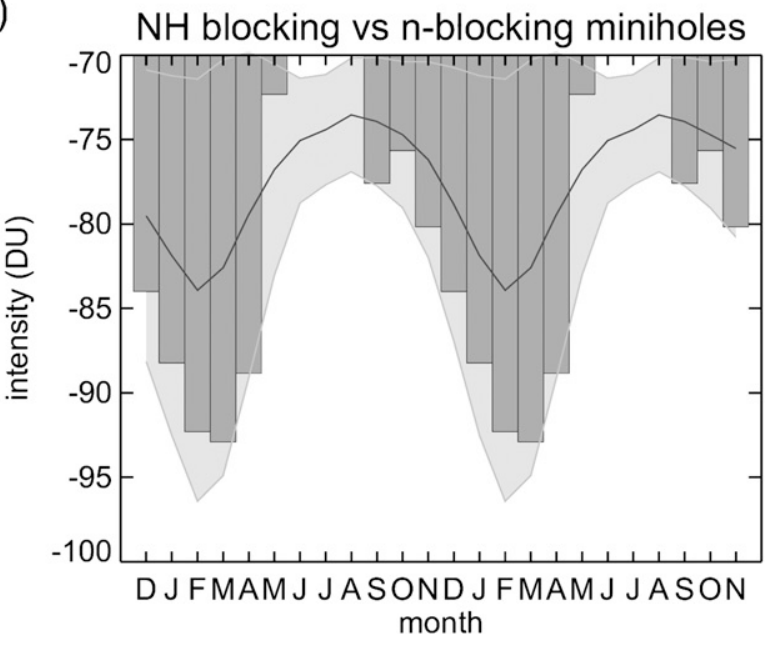

FIG. 5. Mean annual cycle of the (a) frequency, (b) duration, and (c) intensity of $\mathrm{NH}$ ozone minihole events. Gray bars refer to blocking ozone miniholes. Solid lines are for all ozone miniholes in (a) and for nonblocking ozone miniholes in (b) and (c), with shaded areas representing the mean \pm 1 -standard-deviation level. For the sake of visibility, two annual cycles are shown in each panel.
TABLE 1. Seasonal DJFM mean parameters (rows) for regional and hemispheric (columns) ozone minihole events during blocking/ nonblocking situations. Numbers in boldface indicate significant differences at the $p<0.05$ level after a two-tailed Student's $t$ test. Parentheses in the column headers represent the percentage of ozone minihole events concurrent with the blocking.

\begin{tabular}{lccc}
\hline & EUR (33.7\%) & PAC (16.1\%) & NH $(23.1 \%)$ \\
\hline Duration (days) & $\mathbf{4 . 6 / 2 . 7}$ & $3.0 / 3.1$ & $\mathbf{4 . 4 / 2 . 6}$ \\
Extension (10 $\mathrm{km}^{2}$ ) & $\mathbf{4 . 8 / 3 . 2}$ & $3.9 / 3.0$ & $\mathbf{4 . 7 / 3 . 0}$ \\
Intensity (DU) & $\mathbf{- 8 8 . 9 /}-\mathbf{8 2 . 8}$ & $-84.5 /-80.7$ & $\mathbf{- 8 9 . 0 / - 8 2 . 2}$
\end{tabular}

The statistical linkage between blocking and ozone miniholes also displays a spatially dependent pattern. Figure 6 shows the fraction of DJFM ozone minihole days coexisting with blocking at any grid point. The cooccurrence of both systems is more frequent in the EuroAtlantic than in the Pacific basin and is high than in the middle latitudes. The likelihood of simultaneous occurrence peaks over the Scandinavian (Alaska) Peninsula, where as much as $50 \%(40 \%)$ of the ozone miniholes are related to blocking patterns. As high latitudes tend to imprint a more persistent and intense character onto the ozone miniholes (e.g., Petzoldt et al. 1994; James et al. 2000), the distinctive parameters of blocking ozone miniholes (Fig. 5) seem to reflect their spatial preference to occur at high latitudes and the characteristic regions and time scales of blocking occurrence.

In spite of a substantial number of ozone miniholes being caused by regional blocking, the latter does not account for a significant fraction of the variability of the former on interannual time scales (i.e., the wintertime series of blocking and ozone minihole days do not show significant correlations). This is not surprising, considering that blocking ozone minihole events represent less than two-thirds of all occurrences. On longer time scales, the analysis reveals that the winter frequency of days with ozone miniholes over EUR has increased in the last decades (Table 2), in agreement with previous studies (e.g., Brönnimann and Hood 2003), although the trend is not significant and far from linear (i.e., interannual variability dominates). To quantify the blocking contribution to the long-term ozone minihole variability, a linear regression has also been computed for those ozone miniholes unrelated to blocking (Table 2). Surprisingly, the increasing trend in the total number of winter ozone minihole days over EUR is reduced by nearly a factor of 3 when blocking ozone miniholes are removed from the original series. These results are confirmed by a Mann-Kendall test.

Several causes may explain the contribution of blocking ozone miniholes to the total trend: 1) an increase in blocking would bring a concurrent increase in the number of blocking ozone miniholes, assuming that their cooccurrence is independent of external factors (i.e., the likelihood 


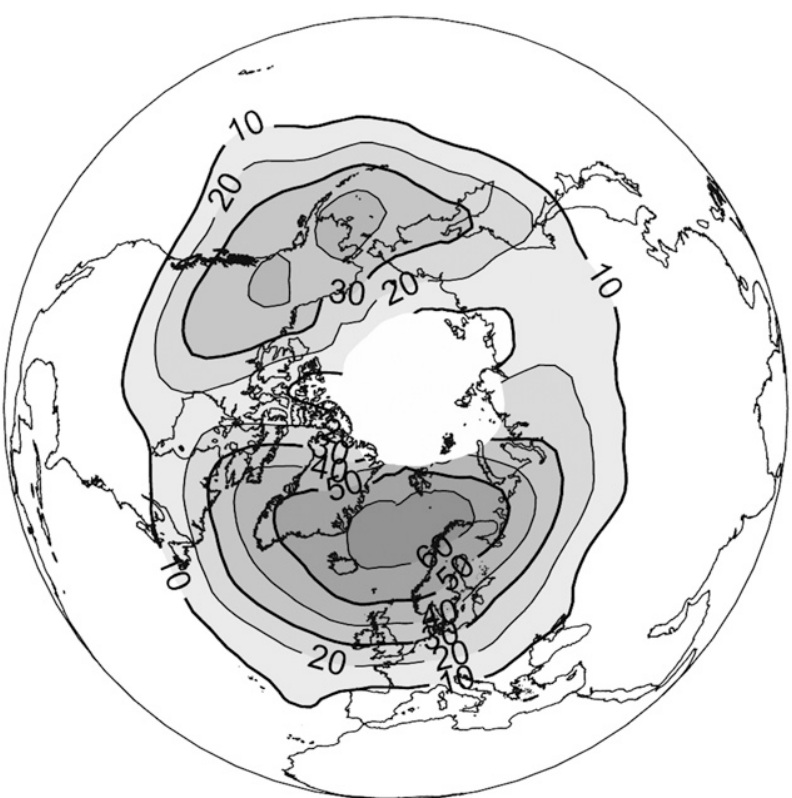

FIG. 6. Mean rate (\%) of DJFM ozone minihole days associated with blocking. The percentage is relative to the local mean frequency of ozone miniholes. Only grid points with climatological frequencies above $1 \%$ are shown.

of cooccurrence is nearly independent of time), however, 2) most (approximately two-thirds) of the blocking trend is explained by blocks unrelated to ozone miniholes (not shown); in other words, the number of blocking ozone miniholes does not increase accordingly, but at faster rates than that expected from the total blocking trend. To further prove this point, the wintertime series of ozone minihole days has been reconstructed $N_{\mathrm{mh}-r}$ as follows:

$$
N_{\text {mh-r }}=N_{\text {nb-mh }}+f N_{b} \text {, }
$$

where $N_{\text {nb-mh }}\left(N_{b}\right)$ is the number of nonblocking ozone miniholes (total blocks) for each year and $f$ is a constant estimated from the mean rate of observed blocks with ozone miniholes. The reconstructed time series reveals a trend that is approximately one-half of that observed (Table 2), indicating that the blocking trend is unable to explain the total increase in blocking ozone miniholes. Furthermore, the variance of the reconstructed series is reduced by more than $10 \%$ as compared to the original one. Thus, other factors must be exerting an influence on the probability of association between blocking and ozone miniholes. This hypothesis implies the interplay of a third agent forcing variability in the coupling. Some feasible factors are discussed in the last section.

Finally, it could also be asked whether blocking ozone miniholes exhibit different spatial signatures as compared
TABLE 2. Long-term linear trend (\%) and interannual variance (\%) of the DJFM time series of EUR ozone miniholes for all, nonblocking, and blocking-based reconstructed ozone miniholes. Variance is expressed in percentage of the observed one for all ozone miniholes.

\begin{tabular}{lccc}
\hline & All & Nonblocking & Reconstructed \\
\hline Long-term trend (\%) & 28.7 & 10.4 & 16.1 \\
Interannual variance (\%) & 100 & 86.5 & 89.8 \\
\hline
\end{tabular}

to nonblocking ozone miniholes. To fingerprint their morphological aspects, composites of $\theta$ fields using a frame of reference relative to the center of the ozone minihole have been carried out (Fig. 7). To do that, daily $\theta$ fields with ozone miniholes are shifted to a grid whose origin coincides with the center of the ozone minihole. Geometrical adjustments to correct for the latitudinal position of individual ozone miniholes are not made since they are only required for distances beyond approximately $40^{\circ}$ (Altenhoff et al. 2008). To obtain similar sample sizes, all days of a given ozone minihole event are included in the corresponding composite.

Blocking ozone miniholes are associated with a pronounced reversal in the meridional $\theta$ field and long-range excursions of high- $\theta$ air from the subtropics. Conversely, wave amplifications of moderate amplitude near the region of enhanced $\theta$ gradient (i.e., the jet stream) are more characteristic of nonblocking ozone miniholes. The discrepancy in the mean $\theta$ values of both composites reflects their preferred locations relative to the jet stream, blocking (nonblocking) ozone miniholes being more common at high (mid-) latitudes. Therefore, the smallscale transient ozone miniholes of midlatitudes are not expected to occur contemporaneously with blocking, but with weather systems more characteristic of the synoptic scale. The composited tracks of ozone miniholes in Fig. 7 are also suggestive of faster-propagating systems during nonblocking ozone miniholes. An immediate consequence is that nonblocking ozone miniholes tend to experience faster but briefer TOC decreases at a given location.

\section{d. Dynamical contributions to blocking ozone miniholes}

As stated in the introduction, ozone miniholes are mainly explained by two dynamical processes: 1) isentropic transport of low ozone values due to the horizontal advection of subtropical air around the tropopause and the southward advection of polar air in the middle stratosphere (Peters et al. 1995; Hood et al. 1999; James et al. 2000) and 2) local adiabatic uplifting of the tropopause and isentropic surfaces in the lower and middle stratosphere by 
a)

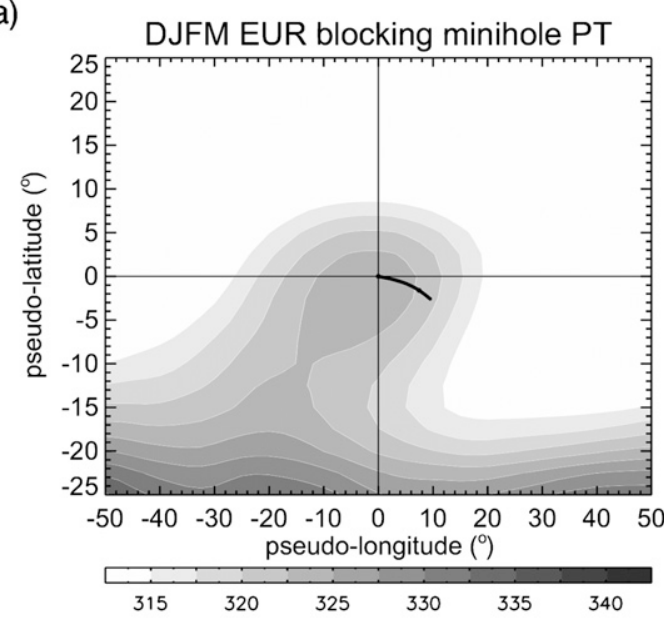

c)

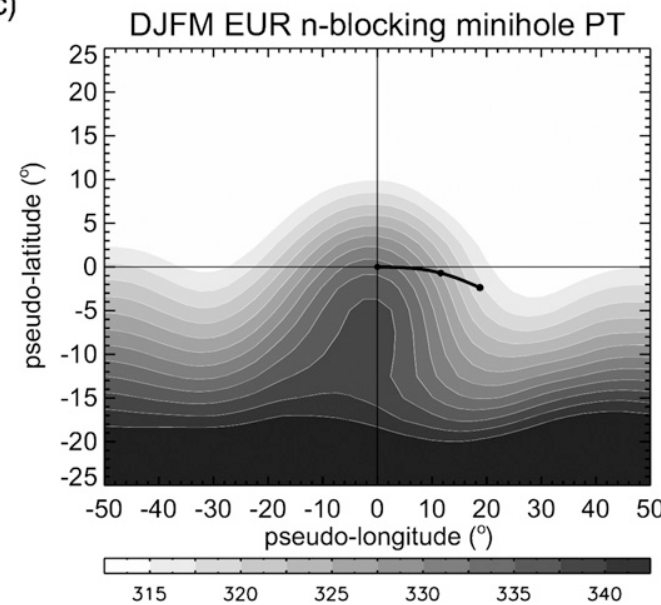

b)

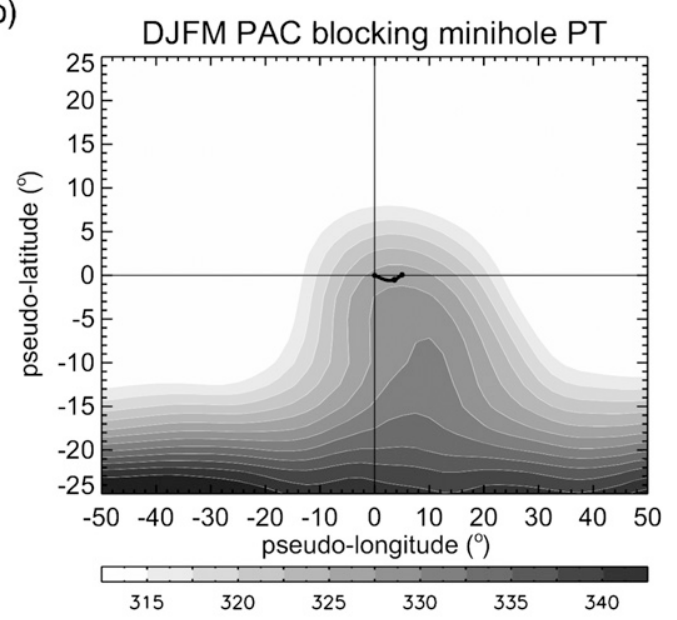

d)

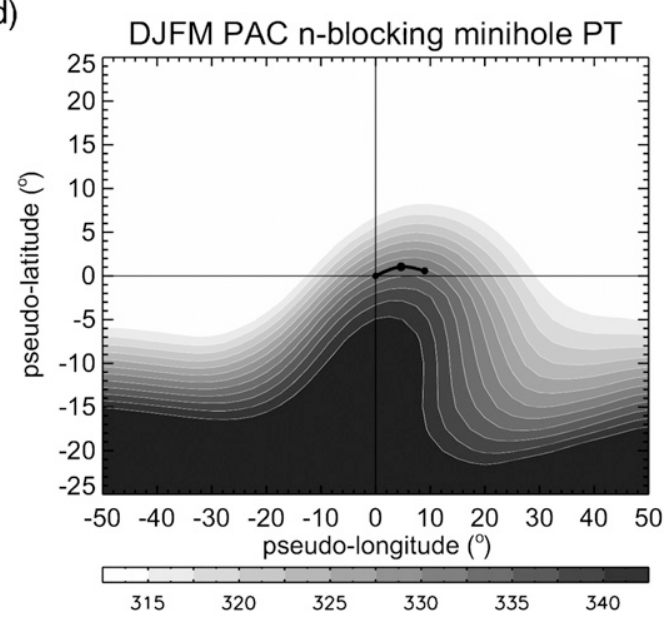

FIG. 7. DJFM composite of $\theta$ on a 2-PVU surface (K) for blocking ozone minihole events in (a) EUR and (b) PAC and for nonblocking ozone minihole events in (c) EUR and (d) PAC. The grid origin is placed at the center of the minihole. Only $\theta>315 \mathrm{~K}$ is shown. Solid lines and dots represent the mean track and center location for the first 3 days of the life cycle, respectively. Note that the grid is displayed in degrees and therefore tracks at high (mid-) latitudes imply shorter (longer) zonal distances than are apparent in the plot.

upward vertical air motions that cause a flow divergence of ozone-rich stratospheric air out of the column and a larger column fraction of tropospheric ozone-poor air (Reed 1950; Petzoldt et al. 1994; Hood et al. 2001). Although the relative contribution of each process varies from case to case, ozone miniholes are typically caused by the superposition of both effects (e.g., Iwao and Hirooka 2006). Here, a simple method is employed to estimate the quantitative dynamical contribution of isentropic transport and vertical uplift for blocking and nonblocking ozone miniholes. The method is based on the decomposition of isentropic ozone density anomalies (Allen and Nakamura 2002; Iwao and Hirooka 2006):

$$
\sigma_{\mathrm{O} 3}^{\prime}=(\sigma \chi)^{\prime}=\sigma \chi-\overline{(\sigma \chi)}=\bar{\sigma} \chi^{\prime}+\sigma^{\prime} \bar{\chi}+\sigma^{\prime} \chi^{\prime}-\overline{\sigma^{\prime} \chi^{\prime}},
$$

where $\chi$ is the ozone mixing ratio and $\sigma$ is the air mass per unit area (the so-called air density in isentropic coordinates, i.e., $\sigma=-g^{-1} \partial p / \partial \theta$, where $g$ and $p$ are the acceleration due to gravity and the pressure, respectively). The prime denotes the anomaly, and the bar denotes the monthly mean. The first term on the righthand side of Eq. (3) (term A hereafter) represents the isentropic transport, whereas the second term (term B hereafter) is the change of the air mass in isentropic layers. The remaining terms are much smaller (Iwao and Hirooka 2006) and, hence, they are ignored here. Note that the terms in the equation involve only the redistribution of ozone, not chemical destruction, and they just provide an approximate estimate, since Eq. (3) implies conservation over a month that might not apply in some cases. High intercase variability is also expected 
depending on the specific weather situation and the latitude where the ozone minihole occurs. Finally, the spatial resolution and the lack of upper-stratospheric data in the ERA-40 reanalysis may mask or miss some peaks in ozone reduction.

For each blocking ozone minihole, daily dynamical profiles have been reconstructed at the grid point with the minimum TOC anomaly. The contribution of each term in Eq. (3) is determined at each half isentropic level in Dobson units per Kelvin. The estimated ozone density anomalies are then compared to those of nonblocking ozone minihole episodes to infer differences in the dynamical processes operating under blocking action. The averaged profiles for regional blocking ozone minihole events are shown in Fig. 8. In spite of the large diversity of cases (deviation of the composited profiles), the ozone amount is reduced above the tropopause, especially in the lower stratosphere. The ozone reduction due to the isentropic transport peaks near the tropopause and in the lower stratosphere, reflecting the poleward advection of ozone-poor air above the tropopause, but it extends well above $500 \mathrm{~K}$, where polar air is transported equatorward (since the meridional ozone gradient is reversed in the stratosphere). The vertical displacement effect reduces the ozone in the lower to middle stratosphere and increases it near the tropopause, as the uplift in the lower stratosphere is accompanied by a corresponding descent of isentropes in the tropopause (e.g., James and Peters 2002).

Additional estimates of each dynamical term have been obtained by computing ozone changes in Dobson units from the thickness $\Delta \theta$ of the isentropic layers and then deducing their contribution to the reconstructed ozone decrease at the $330-850-\mathrm{K}$ column by vertical integration. Table 3 shows their relative contribution to the $330-850-\mathrm{K}$ ozone column. Note that the sum of the dynamical ozone decreases can exceed the reconstructed one since multiplicative terms in Eq. (3) not considered here have counteracting effects (e.g., Allen and Nakamura 2002). On average, the isentropic transport effect in blocking ozone miniholes is found to be the main dynamical contributor, explaining almost two-thirds of the dynamical ozone reduction in the considered column, whereas the ozone decrease caused by the uplift of the isentropes is of secondary importance. Nonblocking ozone miniholes are even more strongly dominated by isentropic transport. Accordingly, it is the larger role played by vertical motions that distinguishes blocking from other kinds of circulation systems responsible for the development of ozone miniholes. This peculiarity seems to be especially conspicuous in EUR, where blocking ozone miniholes show a similar contribution by both mechanisms, whereas in PAC the vertical motion a)

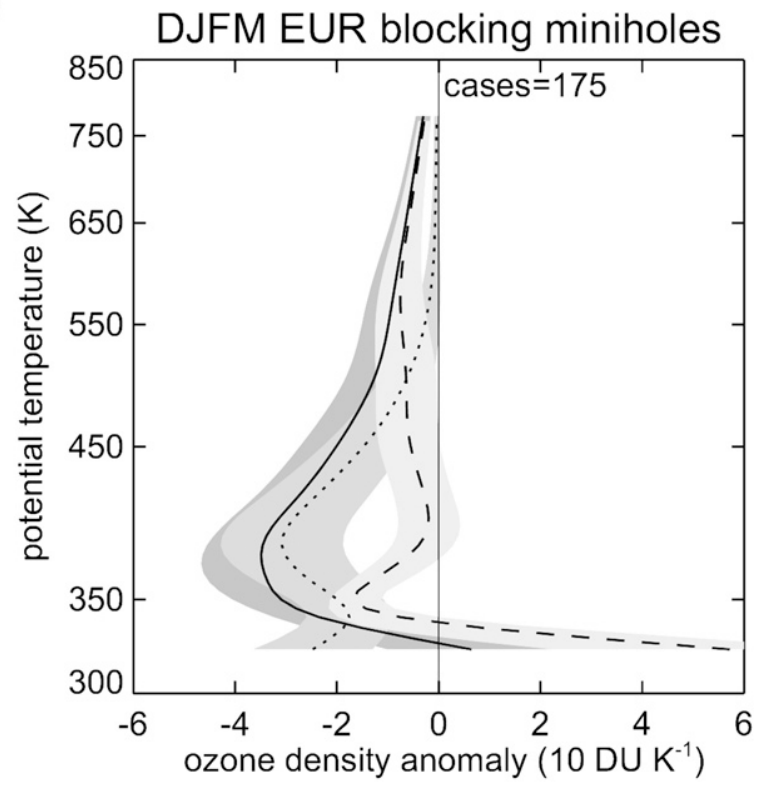

b)

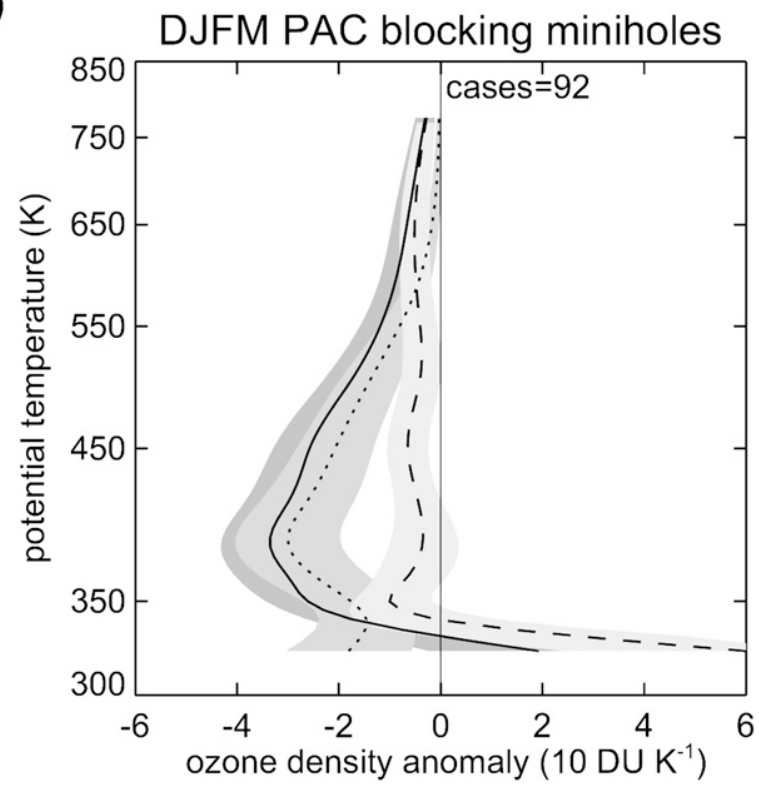

FIG. 8. Composites of the dynamically estimated vertical profiles of ozone decreases (DU K ${ }^{-1}$ ) for DJFM blocking ozone minihole events in (a) EUR and (b) PAC. Only levels above $315 \mathrm{~K}$ are plotted. Solid, dotted, and dashed lines represent the reconstructed ozone anomaly $(\sigma \chi)^{\prime}$, the contribution of the isentropic transport $\bar{\sigma} \chi^{\prime}$, and the contribution of vertical displacement $\sigma^{\prime} \bar{\chi}$, with \pm 0.5 standard-deviation levels indicated by dark-, medium-, and lightshaded areas, respectively. See the text for details.

effect is smaller relative to the isentropic transport term. The reason for this discrepancy may be related to interbasin blocking differences. Because the tropopause height provides an excellent indicator of the uplifting effect (e.g., Steinbrecht et al. 1998), a measure of the latter may be 
TABLE 3. Mean DJFM contribution of dynamical factors (columns) to the ozone reduction in the 330-850-K column for regional (rows) blocking/nonblocking ozone minihole events. The right column represents the reconstructed ozone column reduction (DU) obtained by vertical integration. Values in the three middle columns refer to isentropic transport of ozone-poor air [term A in Eq. (3)], changes in air mass due to vertical uplift [term B in Eq. (3)], and their sum, respectively, and are expressed as percentages of reconstructed ozone column reduction.

\begin{tabular}{llccc}
\hline \hline & $\bar{\sigma} \chi^{\prime}(\%)$ & $\sigma^{\prime} \bar{\chi}(\%)$ & $\bar{\sigma} \chi^{\prime}+\sigma^{\prime} \bar{\chi}(\%)$ & $\sum\left[(\sigma \chi)^{\prime}\right]_{\theta}(\mathrm{DU})$ \\
\hline EUR & $59.3 / 75.8$ & $43.2 / 25.1$ & $102.5 / 100.9$ & $-63.4 /-66.1$ \\
PAC & $70.1 / 74.1$ & $32.0 / 25.4$ & $102.1 / 99.5$ & $-68.0 /-69.4$ \\
\hline
\end{tabular}

inferred from the intensity of the anticyclonic circulation. Therefore, the additional fraction of ozone reduction caused by vertical motions in EUR may be attributed to the observational fact that winter Euro-Atlantic blocks are more intense than their Pacific counterparts (Tyrlis and Hoskins 2008a).

The sum of both dynamical terms explains most of the reconstructed ozone anomaly, thus confirming that blocking ozone miniholes also have an almost entirely dynamical origin (e.g., Salby and Callaghan 1993; Bojkov and Balis 2001; Hood et al. 2001). However, there is still a discrepancy between the dynamical reconstruction and the actual TOC decrease (cf. Tables 1 and 3), which can exceed $25 \%$ of the observed TOC reduction. Such disagreement is much more pronounced in blocking than in nonblocking ozone miniholes and in EUR than in PAC. In addition to systematic biases introduced by the methodological approach (e.g., the dynamical analysis does not include the entire atmospheric column), other factors may contribute to the ozone losses. Among them, several chemical ozone mechanisms have been reported as a source of ozone depletion outside the polar vortex, including (i) in situ heterogeneous chemical destruction from halogen activation on liquid sulfate aerosols or cirrus (Solomon 1999) and (ii) dilution into lower latitudes of ozone-depleted air activated within the Arctic vortex (Grewe et al. 1998; Hadjinicolaou and Pyle 2004). These processes seem to be more effective in ozone miniholes at high latitudes (Teitelbaum et al. 2001; Keil et al. 2007), where they might account up to one-third of the extratropical TOC depletion (Stenke and Grewe 2004). The persistent and high-latitudinal character of the blocking and the lower fraction of ozone reduction explained by dynamical factors in blocking ozone miniholes are suggestive of an indirect secondary role of the chemical processes, especially in EUR, where equatorward displacements of the polar vortex are commonly involved in ozone miniholes (e.g., Petzoldt 1999; James et al. 2000). However, further studies are required to quantify this effect.

\section{e. Discussion on factors associated with blocking ozone miniholes}

Up to now, our analysis has focused on highlighting distinctive features that are common to blocking ozone miniholes. However, little has been said about what specific aspects cause some blocks to trigger ozone miniholes. An analysis similar to that performed in the previous sections has therefore been carried out to determine whether some blocks are more prone to develop ozone miniholes. In terms of dynamical factors (Fig. 9), the most remarkable difference is the tendency for EUR blocks with ozone miniholes to exhibit more efficient vertical motions than those without ozone miniholes. This contribution is well collocated with the blocking center, whereas ozone reductions due to isentropic ozone transport occur slightly west of the blocking center, reflecting the upstream branch of the meridional flow associated with the block. Over the PAC sector, where the vertical effect is secondary, a noteworthy enhancement of isentropic transport is also required to drive ozone miniholes (not shown). On the other hand, the mean parameters of blocking events with ozone miniholes do not present statistically significant differences, although they tend to show greater persistence, intensity, and size. The morphology of both subsets of blocks is also similar.

These results suggest that the association between blocks and ozone miniholes may be caused by the interplay of a third factor. As discussed previously, the most striking feature of blocking ozone miniholes is their high-latitudinal character. A common signature in this type of ozone miniholes is the occurrence of sudden stratospheric warming events or other distortion of the polar vortex (e.g., Peters et al. 1995; Grewe and Dameris 1997; James et al. 2000; Semane et al. 2002), which may also favor chemical ozone depletion (Teitelbaum et al. 2001; Stenke and Grewe 2004). In that sense, the equivalent latitude (EL), which considers the area enclosed within a given PV contour on a $\theta$ surface, provides a very useful vortex-tracking tool (Lary et al. 1995; Nash et al. 1996). With the aim of exploring whether blocks with ozone miniholes are related to specific configurations of the polar vortex, EL composites for blocking days with and without ozone miniholes have been computed at each basin. In the lower stratosphere (not shown), EL values around the blocked area are lower when ozone miniholes are concurrent with the block, indicating that air parcels with subtropical origins are transported to higher latitudes more efficiently than during blocks without ozone 
a)

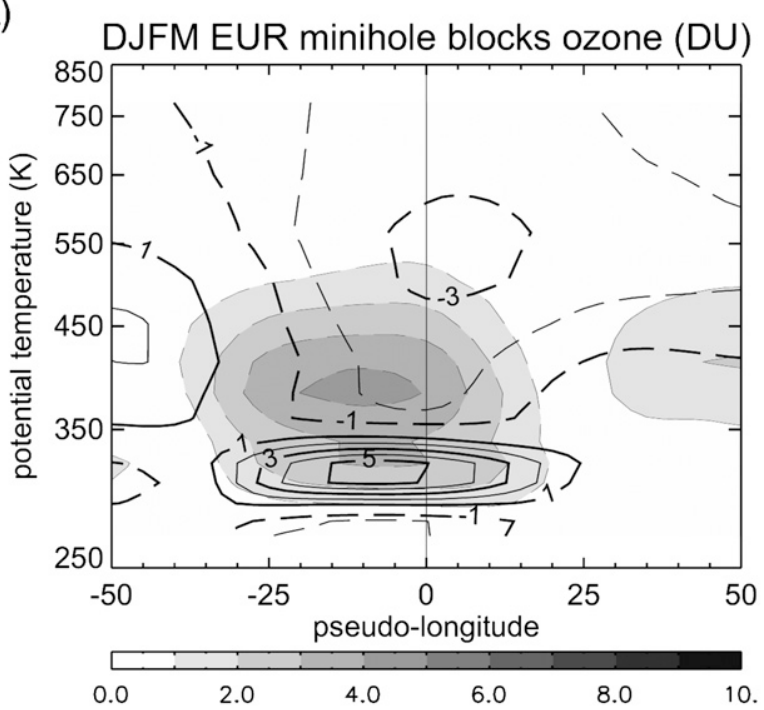

b)

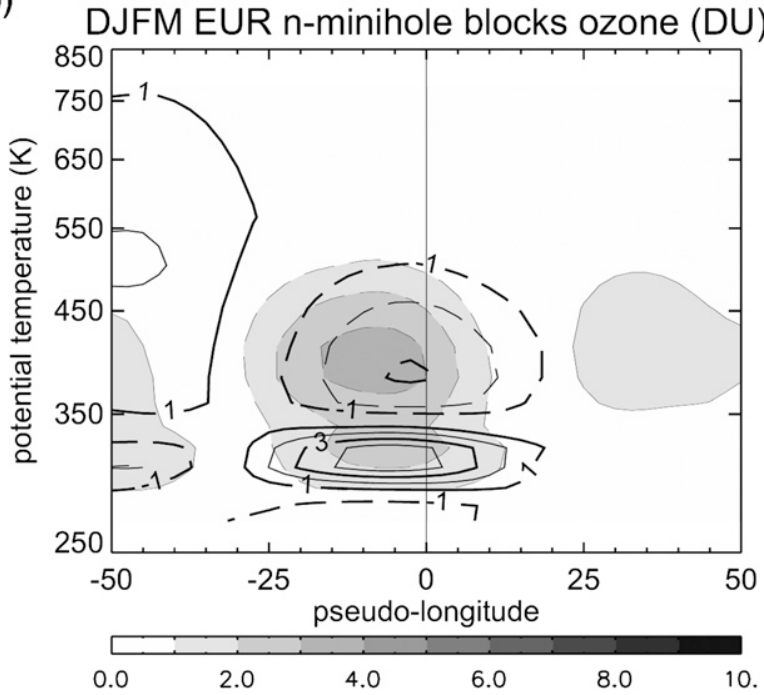

FIG. 9. Longitude- $\theta$ vertical cross-section composites of the estimated ozone decreases (DU) during DJFM blocking events (a) with and (b) without ozone miniholes. The origin of the grid is located at the center of the block. Contours (shaded areas) represent the estimated dynamical contribution of vertical displacement (isentropic transport) effect. Solid (dashed) lines indicate an ozone increase (decrease).

miniholes. Above $500 \mathrm{~K}$ (Fig. 10), the advection arises from higher latitudes and it is stronger for blocks with ozone miniholes.

Moreover, blocking ozone miniholes occur in association with southward shifts of the polar vortex, as seen if the polar vortex edge is delineated by the EL contour of $65^{\circ}$ (Lary et al. 1995). Over EUR, the mean location of the ozone miniholes associated with blocking (white dot in Fig. 10) lies between the polar vortex edges of each of the composites, indicating that the polar vortex covered the ozone minihole region during the block action. In PAC, ozone miniholes occur too far south of the polar vortex and, hence, the role of the latter is expected to be negligible there. James et al. (2000) found that a southward shift of the polar vortex along the Europe-Canada axis had important effects on the TOC levels of Europe and North America. However, while a shift toward Europe reflected an anticyclonic pattern over northwestern Europe, the corresponding North Pacific ridge was not notably enhanced in displacements toward Canada, thus pointing to a relative decoupling between PAC blocking and the polar vortex.

Therefore, the configuration of the polar vortex may provide an explanation for the different couplings seen between ozone miniholes and blocking in the two regions. Due to the mean position of the polar vortex and the typical high latitudes of blocks, the simultaneous spatial coincidence of blocking and a displaced polar vortex aloft is expected to be favored in the EUR sector. As blocks are also more frequent in EUR than in PAC, the polar vortex may account to some extent for the spatial asymmetry in the distribution of high-latitude ozone miniholes. The polar vortex also emerges as a candidate to explain the enhanced coupling between EUR blocking and ozone miniholes at the end of the period analyzed. In this regard, several changes in the Arctic winter stratosphere have been reported, including increases in the vortex size (e.g., Harris et al. 2008), although they depend on the length of the record considered.

On the other hand, some dependence between blocking and specific configurations of the polar vortex cannot be ignored. For instance, several studies have identified blocks as important precursors of stratospheric sudden warming events, via the upward propagation of phaselocked planetary waves at typical regions of blocking that either split or shift the polar vortex (e.g., Martius et al. 2009; Woollings et al. 2010, and references therein). Therefore, the displacement of the polar vortex could be a consequence of blocking rather than an independent mechanism. As a tentative approach aimed at determining whether regional blocking occurrence (either alone or in simultaneous occurrence) is inherent to polar vortex perturbations, composite differences of EL distributions between blocking and nonblocking days have been calculated (not shown). Blocking is accompanied by appreciable but more modest shifts of the polar vortex than those in Fig. 10, indicating that EUR and PAC blocking do not frequently reach enough amplitude to perturb the polar vortex. It rather seems that, in most cases, blocking by itself is not able to account for the displacement of the polar vortex and, hence, vortex displacement events must occur independently of blocking at least some of the time. However, this statement 
a)

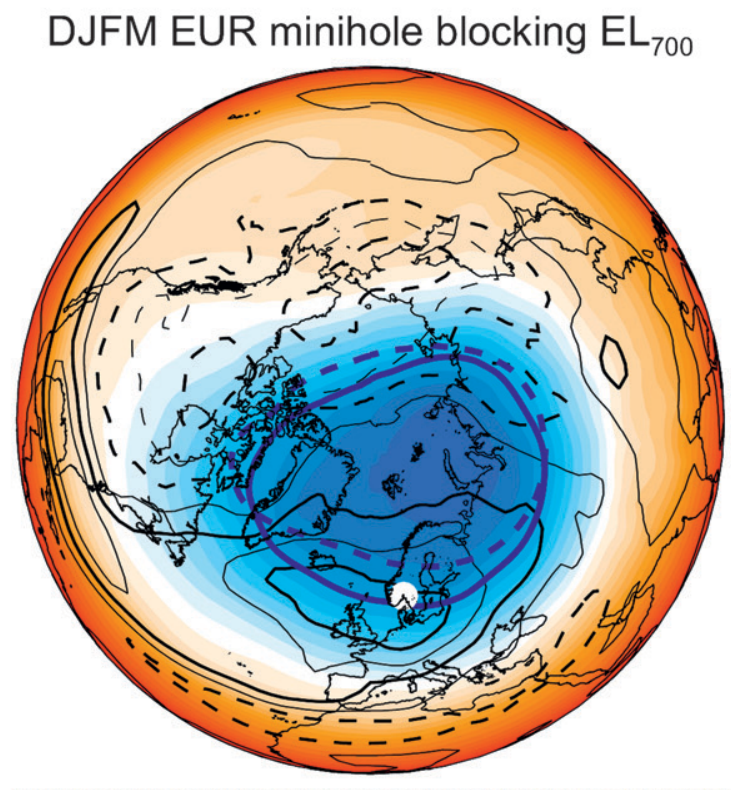

$0 \quad 51015202530354045505560657075808590$

b)

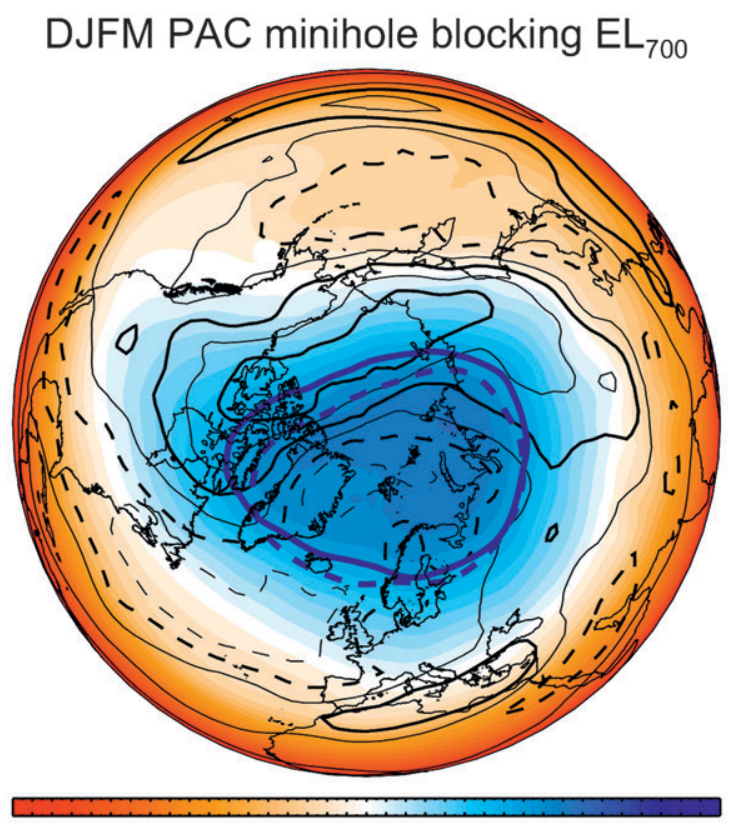

051015202530354045505560657075808590

FIG. 10. Composite of EL distribution at $700 \mathrm{~K}$ (shaded areas) for DJFM blocking ozone minihole days in (a) EUR and (b) PAC. Black contours represent the composite difference between blocks with and blocks without ozone miniholes, and solid (dashed) lines indicate positive (negative) EL values with CIs of $2^{\circ}$ (the $0^{\circ}$ isoline is omitted). The solid (dashed) thick blue line marks the location of the polar vortex estimated from the $65^{\circ} \mathrm{EL}$ isoline of the composite for blocks with (without) ozone miniholes. White dots demark the mean positions of the blocking ozone miniholes. does not mean that specific vortex disturbances cannot be aided by certain blocks. Martius et al. (2009) and Woollings et al. (2010) pointed to Atlantic (rather than EUR) blocking as a possible precursor of sudden warming events, and hence, the linkage may also be region sensitive. These results suggest that the difference between blocking with and without ozone miniholes does not strictly depend on the characteristics of the block. In other words, whereas blocking favors ozone minihole occurrence, additional factors may further enhance or inhibit its cooccurrence.

Some of the differences between PAC and EUR blocking ozone miniholes may also depend on the polar vortex configuration. In particular, the characteristic southward displacements of the polar vortex observed during EUR blocking ozone miniholes are suggestive of an indirect chemical ozone loss over the region where TOC is already reduced by the dynamical effects of the block. Different studies have reported that PSC formation over Scandinavia, induced by quasi-stationary gravity waves under strong flow over the Scandinavian plateau, is a necessary condition for producing significant ozone depletion in the Arctic (Carslaw et al. 1998; Lowe et al. 2006). However, Arctic ozone depletion is typically much smaller than that in the Antarctic and it does not occur every winter (e.g., Tilmes et al. 2006). Therefore, further analyses are required to elucidate and quantify possible chemical influences on the enhanced TOC reductions of blocking ozone miniholes. Furthermore, the circumstances under which blocking and polar vortex shifts coincide, and whether the latter is just a favorable or a necessary condition for blocking ozone miniholes, remain open questions.

\section{Conclusions}

In this study, the statistical and dynamical relationship between TOC and blocking is explored in the Northern Hemisphere by employing data from the ERA-40 for the 1978-98 period. Blocking signals in three different statistics of TOC, including its mean and extreme distribution and an objective definition of ozone miniholes, are described, with special emphasis on the extended winter season and the European and eastern Pacific-North America sectors. The main conclusions are as follow:

1) Regional blocking occurrence is accompanied by a lowering of the mean TOC within the anticyclonic circulation region and an enhancement of ozone upstream and downstream (upstream and south) in the PAC (EUR) sector. The distinctive regional blocking signatures in TOC mirror the preference for different types of blocking patterns to dominate over each basin. 
2) Regarding the TOC extreme distribution, blocking enhances (reduces) the occurrence of TOC minima over the same areas that experience a reduction (increase) in TOC. The region most susceptible of experiencing low extreme values of TOC during EUR (PAC) blocking regimes is the Scandinavian (Alaska) Peninsula, where more than $50 \%$ of blocking days cause TOC decreases below its lower tercile. Conversely, blocking is not associated with the occurrence of TOC minima in the western Mediterranean (central and eastern North America).

3) Blocking accounts for a considerable fraction of the ozone miniholes and they are among the most intense, persistent, and extensive. The relationship between ozone miniholes and blocking exhibits a clear spatially dependent pattern, strongly confined to the high latitudes of both basins. On the other hand, nonblocking ozone miniholes are typical of midlatitudes and they are more probably caused by synoptic transient wave breaking near the jet stream with moderate poleward excursions of subtropical air. The degree of coupling is also stronger in EUR than in PAC, with most of the ozone miniholes over Scandinavia happening concurrently with blocking. Further analyses point to the role played by the polar vortex in European blocking ozone minihole development as a feasible candidate to explain this spatially asymmetric coupling.

4) In spite of a substantial number of miniholes being caused by regional blocking, the latter does not account for a statistically significant interannual variability of the former. However, blocking ozone miniholes explain almost two-thirds of the total observed trend in ozone miniholes over EUR, which is larger than that expected from the concurrent increase in blocking. This long-term variability in the coupling suggests the interplay of a third factor modulating the probability of association between both phenomena.

5) Nearly two-thirds of the dynamical reduction of the 330-850-K ozone column in blocking ozone miniholes is due to the transport of air masses with climatologically low ozone, which is poleward near the tropopause and equatorward in the middle stratosphere. The remainder is partially explained by the loss of ozone-rich air due to adiabatic vertical uplift of isentropes in the lower and middle stratosphere. Although the contribution of this effect is of secondary importance, its enhancement is characteristic of blocking ozone miniholes. This pattern is especially marked in EUR, where ozone reductions by vertical motions are of the same magnitude as those caused by isentropic ozone transport.

6) Blocking and nonblocking ozone miniholes share similar dynamical origins. The main distinctive feature seems to be related to the relative contribution of dynamical effects and, in blocking ozone miniholes of EUR, the on-off interplay of the polar vortex, which may also contribute to the enhanced ozone reductions observed in EUR blocking ozone miniholes. On the other hand, the difference between blocking with and without ozone miniholes does not seem to reside exclusively on the specific characteristics of the block but also on additional factors enhancing or inhibiting their coupling.

Acknowledgments. This work has been partially supported by the MICINN (Spanish government) under Projects CGL2007-65891-C05-05/CLI (DB and JAG) and CGL2008-05939-C03-02/CLI (M. Antón). ERA-40 reanalysis data were provided by the ECMWF from their data server Web site (http://www.ecmwf.int/). MA thanks Junta de Extremadura-Consejería de Infraestructuras y Desarrollo Tecnológico-and Fondo Social Europeo for concession of a postdoctoral grant. R. R. García provided helpful comments on this manuscript. Two anonymous reviewers contributed to improving the final version of this paper.

\section{REFERENCES}

Allen, D. R., and N. Nakamura, 2002: Dynamical reconstruction of the record low column ozone over Europe on 30 November 1999. Geophys. Res. Lett., 29, 1362, doi:10.1029/2002GL014935.

Altenhoff, A. M., O. Martius, M. Croci-Maspoli, C. Schwierz, and H. C. Davies, 2008: Linkage of atmospheric blocks and synopticscale Rossby waves: A climatological analysis. Tellus, $\mathbf{6 0 A}$, 1053-1063.

Antón, M., M. L. Cancillo, A. Serrano, J. M. Vaquero, and J. A. García, 2007: Ozone minihole over southwestern Spain during January 2004: Influence over ultraviolet radiation. Geophys. Res. Lett., 34, L10808, doi:10.1029/2007GL029689.

_ A. Serrano, M. L. Cancillo, and J. A. García, 2008: Total ozone and solar erythemal irradiance in southwestern Spain: Day-to-day variability and extreme episodes. Geophys. Res. Lett., 35, L20804, doi:10.1029/2008GL035290.

Appenzeller, C., A. K. Weiss, and J. Staehelin, 2000: North Atlantic Oscillation modulates total ozone winter trends. Geophys. Res. Lett., 27, 1131-1134.

Barriopedro, D., R. Garcia-Herrera, A. R. Lupo, and E. Hernández, 2006: A climatology of Northern Hemisphere blocking. J. Climate, 19, 1042-1063.

_, R. García-Herrera, and R. M. Trigo, 2010: Application of blocking diagnosis methods to general circulation models. Part I. A novel detection scheme. Climate Dyn., in press, doi:10.1007/s00382-010-0767-5.

Bojkov, R. D., and D. S. Balis, 2001: Characteristics of episodes with extremely low ozone values in the northern middle latitudes 1957-2000. Ann. Geophys., 19, 797-897.

Brönnimann, S., and L. L. Hood, 2003: Frequency of low-ozone events over northwestern Europe in 1952-1963 and 1990-2000. Geophys. Res. Lett., 30, 2118, doi:10.1029/2003GL018431. 
Canziani, P. O., R. H. Compagnucci, and A. Bischoff, 2002: A study of impacts of tropospheric synoptic processes on the genesis and evolution of extreme total ozone anomalies over southern South America. J. Geophys. Res., 107, 4741, doi:10.1029/ 2001JD000965.

Carslaw, K. S., and Coauthors, 1998: Increased stratospheric ozone depletion due to mountain-induced atmospheric waves. $\mathrm{Na}$ ture, 391, 675-678.

Croci-Maspoli, M., C. Schwierz, and H. C. Davies, 2007: Atmospheric blocking: Space-time links to the NAO and PNA. Climate Dyn., 29, 713-725.

Dethof, A., and E. V. Hólm, 2004: Ozone assimilation in the ERA40 reanalysis project. Quart. J. Roy. Meteor. Soc., 130, 28512872, doi:10.1256/qj.03.196.

Dobson, G. M. B., D. N. Harrison, and J. Lawrence, 1929: Measurements of the amount of ozone in the earth's atmosphere and its relation to other geophysical conditions: Part III. Proc. Roy. Soc. London, 122A, 456-486.

Engelen, R. J., 1996: The effect of planetary waves on the total ozone deviations in the presence of a persistent blocking anticyclone system. J. Geophys. Res., 101 (D22), 28 775-28 784.

Farman, J. C., B. G. Gardiner, and J. D. Shanklin, 1985: Large losses of total ozone in Antarctica reveal seasonal $\mathrm{ClOx}=$ NOx interaction. Nature, 315, 207-210.

— A. O'Neill, and R. Swinbank, 1994: The dynamics of the arctic polar vortex during the EASOE campaign. Geophys. Res. Lett., 21, 1195-1198.

Fusco, A. C., and M. L. Salby, 1999: Interannual variations of total ozone and their relationships to variations of planetary wave activity. J. Climate, 12, 1619-1629.

Grewe, V., and M. Dameris, 1997: Heterogeneous PSC ozone loss during an ozone minihole. Geophys. Res. Lett., 24, 2503-2506.

- _ - and R. Sausen, 1998: Impact of stratospheric dynamics and chemistry on Northern Hemisphere midlatitude ozone loss. J. Geophys. Res., 103, 25 417-25 433.

Hadjinicolaou, P., and J. A. Pyle, 2004: The impact of Arctic ozone depletion on northern middle latitudes: Interannual variability and dynamical control. J. Atmos. Chem., 47, 25-43.

Harris, N. R. P., and Coauthors, 2008: Ozone trends at northern mid- and high latitudes-A European perspective. Ann. Geophys., 26, 1207-1220.

Hood, L. L., and B. E. Soukharev, 2005: Interannual variations of total ozone at northern midlatitudes correlated with stratospheric EP flux and potential vorticity. J. Atmos. Sci., 62, 3724-3740.

_ J. P. McCormack, and K. Labitzke, 1997: An investigation of dynamical contributions to midlatitude ozone trends in winter. J. Geophys. Res., 102, 13 079-13 093.

— S. Rossi, and M. Beulen, 1999: Trends in lower stratospheric zonal winds, Rossby wave breaking behavior and column ozone at northern midlatitudes. J. Geophys. Res., 104, 24 32124339.

- B. E. Soukharev, M. Fromm, and J. P. McCormack, 2001: Origin of extreme ozone minima at middle to high northern latitudes. J. Geophys. Res., 106, 20 925-20 940.

Hudson, R. D., M. F. Andrade, M. B. Follette, and A. D. Frolov, 2006: The total ozone field separated into meteorological regimes-Part II: Northern Hemisphere mid-latitude total ozone trends. Atmos. Chem. Phys., 6, 5183-5191.

Iwao, K., and T. Hirooka, 2006: Dynamical quantifications of ozone minihole formation in both hemispheres. J. Geophys. Res., 111, D02104, doi:10.1029/2005JD006333.

James, P. M., 1998: A climatology of ozone miniholes over the Northern Hemisphere. Int. J. Climatol., 18, 1287-1303.
— , and D. Peters, 2002: The Lagrangian structure of ozone miniholes and potential vorticity anomalies in the Northern Hemisphere. Ann. Geophys., 20, 835-846.

,-- , and D. W. Waugh, 2000: Very low ozone episodes due to polar vortex displacement. Tellus, 52B, 1123-1137.

Keil, M., D. R. Jackson, and M. C. Hort, 2007: The January 2006 low ozone event over the UK. Atmos. Chem. Phys., 7, 961-972.

Koch, G., H. Wernli, C. Schwierz, J. Staehelin, and T. Peter, 2005: A composite study on the structure and formation of ozone miniholes and minihighs over central Europe. Geophys. Res. Lett., 32, L12810, doi:10.1029/2004GL022062.

Krzyscin, J. W., 2002: Long-term changes in ozone minihole event frequency over the Northern Hemisphere derived from ground-based measurements. Int. J. Climatol., 22, 14251439.

Lary, D. J., M. P. Chipperfield, J. A. Pyle, W. A. Norton, and L. P. Riishojgaard, 1995: Three-dimensional tracer initialization and general diagnostic using equivalent PV latitudepotential temperature coordinates. Quart. J. Roy. Meteor. Soc., 121, 187-210

Lowe, D., A. R. MacKenzie, H. Schlager, C. Voigt, A. Dornbrack, M. J. Mahoney, and F. Cairo, 2006: Liquid particle composition and heterogeneous reactions in a mountain wave polar stratospheric cloud. Atmos. Chem. Phys., 6, 3611-3623.

Martius, O., L. M. Polvani, and H. C. Davies, 2009: Blocking precursors to stratospheric sudden warming events. Geophys. Res. Lett., 36, L14806, doi:10.1029/2009GL038776.

McCormack, J. P., and L. L. Hood, 1997: The frequency and size of ozone "minihole" events at northern midlatitudes in February. Geophys. Res. Lett., 24, 2647-2650.

Nash, E. R., P. A. Newman, J. E. Rosenfield, and M. R. Schoeberl, 1996: An objective determination of the polar vortex using Ertel's potential vorticity. J. Geophys. Res., 101, 94719478.

Newman, P. A., L. R. Lait, and M. R. Schoeberl, 1988: The morphology and meteorology of Southern Hemisphere spring total ozone miniholes. Geophys. Res. Lett., 15, 923-926.

Orsolini, Y. J., and V. Limpasuvan, 2001: The North Atlantic Oscillation and the occurrences of ozone miniholes. Geophys. Res. Lett., 28, 4099-4102.

_ patterns over the Euro-Atlantic sector in the spring. Quart. J. Roy. Meteor. Soc., 129, 3251-3263.

_ , and G. Nikulin, 2006: A low ozone episode during the European heatwave of August 2003. Quart. J. Roy. Meteor. Soc., 132, 667-680.

- D. B. Stephenson, and F. J. Doblas-Reyes, 1998: Storm tracks signature in total ozone during Northern Hemisphere winter. Geophys. Res. Lett., 25, 2413-2416.

— northern high latitudes. Quart. J. Roy. Meteor. Soc., 129, 3265 3276.

Pelly, J., and B. Hoskins, 2003: A new perspective on blocking. J. Atmos. Sci., 60, 743-755.

Peters, D., and D. W. Waugh, 1996: Influence of barotropic shear on the poleward advection of upper-tropospheric air. J. Atmos. Sci., 53, 3013-3031.

— of total ozone in boreal months during 1979-1992. J. Climate, 12, 1038-1048.

_ - J. Egger, and G. Entzian, 1995: Dynamical aspects of ozone minihole formation. Meteor. Atmos. Phys., 55, 205-214. 
Petzoldt, K., 1999: The role of dynamics in total ozone deviations from their long-term mean over the Northern Hemisphere. Ann. Geophys., 17, 231-241.

— , B. Naujokat, and K. Neugebohren, 1994: Correlation between stratospheric temperature, total ozone and tropospheric weather systems. Geophys. Res. Lett., 21, 1203-1206.

Randel, W. J., F. Wu, and R. Stolarski, 2002: Changes in column ozone correlated with the stratospheric EP flux. J. Meteor. Soc. Japan, 80, 849-862.

Reed, R. J., 1950: The role of vertical motions in ozone-weather relationships. J. Meteor., 7, 263-267.

Reid, S. J., A. F. Tuck, and G. Kildaris, 2000: On the changing abundance of ozone minima at northern midlatitudes. J. Geophys. Res., 105, 12 169-12 180.

Rex, D. F., 1950: Blocking action in the middle troposphere and its effect upon regional climate. Part II: The climatology of blocking action. Tellus, 2, 275-301.

Salby, M. L., and P. F. Callaghan, 1993: Fluctuations of total ozone and their relationship to stratospheric air motions. J. Geophys. Res., 98, 2715-2727.

Schwierz, C., M. Croci-Maspoli, and H. C. Davies, 2004: Perspicacious indicators of atmospheric blocking. Geophys. Res. Lett., 31, 6125-6128.

Semane, N., H. Teitelbaum, and C. Basdevant, 2002: A very deep ozone minihole in the Northern Hemisphere stratosphere at mid-latitudes during the winter of 2000. Tellus, 54A, 382-389.

Solomon, S., 1999: Stratospheric ozone depletion: A review of concepts and history. Rev. Geophys., 37, 275-316.

, R. W. Portmann, R. R. Garcia, L. W. Thomason, L. R. Poole, and M. P. McCormick, 1996: The role of aerosol variations in anthropogenic ozone depletion at northern midlatitudes. J. Geophys. Res., 101, 6713-6727.
Staehelin, J., N. R. P. Harris, C. Appenzeller, and J. Eberhard, 2001: Ozone trends: A review. Rev. Geophys., 39, 231-290.

Steinbrecht, W., H. Claude, U. Kohler, and K. P. Hoinka, 1998: Correlations between tropopause height and total ozone: Implications for long-term changes. J. Geophys. Res., 103, $19183-$ 19192.

Stenke, A., and V. Grewe, 2004: Impact of dynamically induced ozone minihole events on PSC formation and chemical ozone destruction. Adv. Space Res., 33, 1062-1067.

Stolarski, R. S., P. Bloomfield, and R. D. McPeters, 1991: Total ozone trends deduced from Nimbus 7 TOMS data. Geophys. Res. Lett., 18, 1015-1018.

Teitelbaum, H., M. Moustaoui, and M. Fromm, 2001: Exploring polar stratospheric cloud and ozone minihole formation: The primary importance of synoptic-scale flow perturbations. J. Geophys. Res., 106, 28 173-28 188.

Tilmes, S., R. Muller, A. Engel, M. Rex, and J. M. Russell III, 2006: Chemical ozone loss in the Arctic and Antarctic stratosphere between 1992 and 2005. Geophys. Res. Lett., 33, L20812, doi:10.1029/2006GL026925.

Tyrlis, R., and B. J. Hoskins, 2008a: Aspects of Northern Hemisphere atmospheric blocking climatology. J. Atmos. Sci., 65, $1638-1652$

, and - 2008b: The morphology of Northern Hemisphere blocking. J. Atmos. Sci., 65, 1653-1665.

Uppala, S. M., and Coauthors, 2005: The ERA-40 Reanalysis. Quart. J. Roy. Meteor. Soc., 131, 2961-3012.

Wilks, D. S., 1995: Statistical Methods in the Atmospheric Sciences. Academic Press, 467 pp.

Woollings, T., A. Charlton-Perez, S. Ineson, A. G. Marshall, and G. Masato, 2010: Associations between stratospheric variability and tropospheric blocking. J. Geophys. Res., 115, D06108, doi:10.1029/2009JD012742. 